\title{
PRIMENA INFORMACIONIH TEHNOLOGIJA U MODERNOM SPORTU
}

\author{
Aleksandar Živković*, \\ Tamara Ratković, \\ Srđan Marković
}

Univerzitet Singidunum, Beograd, Srbija

Odgovorno lice:

Aleksandar Živković

e-pošta:

aleksandar.zivkovic@singidunum.ac.rs

\section{Rezime:}

Informacione tehnologije (IT) u sportu uključene su u sve segmente i to prvenstveno u rad sportista i trenera, a onda i zvaničnika i gledalaca. Sportisti i treneri IT koriste $\mathrm{u}$ treningu kao i na samom takmičenju. U treningu se koristi kroz kontrolu opterećenja, dijagnostiku i analizu, a na takmičenju kroz video tehnologiju, foto-finiš, Hawk-eye, gol-tehnologiju, miCoach Elite System. Tehnologija pomaže stručnjacima da podrže svoje komentare i analize za vreme i nakon igara, te da izvođači preispitaju svoju taktiku i svoje protivnike kako bi utvrdili što trebaju učiniti kako bi poboljšali i formulisali strategiju. Gledalac sportskog događaja nije više pasivan posmatrač kod kuće ili na stadionu. Tehnologija je omogućila gledaocima da imaju aktivniju ulogu u događajima. Pokrivenost događaja mikro-kamerama pruža više uglova gledanja, prate pojedinačne sportiste ili sve izvođače, statističke informacije o pojedincima, utakmici i prethodnim nastupima. Interaktivni softveri - aplikacije nude pristup robama, informacijama, takmičenjima, igrama i glasanju preko veza na ulaznicama i programima ili preko preuzimanja. Pomoću digitalnih medija može se pratiti širok spektar amaterskih i profesionalnih sportova na mnogo različitih načina, na telefonu, tabletu, laptopu, računaru, a društveni mediji dozvoljavaju fanovima da imaju ličnu vezu sa sportistima i klubovima.

Ključne reči:

informacioni sistem, analize, trening, takmičenje, uređaji.

\section{UVOD}

Još od drevne Grčke sport je opčinjavao ljude, a sportisti imali veliki uticaj i status u društvu. Međutim, nakon obnove Olimpijskih igara počela je ekspanzija sporta od amaterizma do profesionalizma, da bi u poslednje vreme prelazio sve granice pojmljive ljudskom umu, dodirujući granice naučne-fantastike. Tehnologija je promenila život uopšte, a tu promenu nisu izbegli ni sportisti. Na današnjem nivou razvoja teško je razdvojiti tehnološku inovaciju i sport, odnosno današnji sport nemoguće je zamisliti bez upliva tehnologije. VAR tehnologija, odela za plivanje od specijalnih materijala koji omogućavaju bolju „plovnost“ tela kroz vodu, čipovi u lopti i obući za analizu kretanja, sve su tehnološka rešenja koja su nezaobilazni elementi priče o sportu. Sveobuhvatno gledano, informacione tehnologije (IT) predstavljaju neophodne resurse za prikupljanje i obradu podataka u cilju realizacije ciljeva sportske organizacije. 
Razvoj novih informacionih sistema i njihov uticaj na sport predstavljaju ogroman potencijal svim učesnicima u sportu u rešavanju problema, nalaženju novih puteva razvoja, usavršavanju performansi, smanjenju grešaka, povećanju zabave.

Glavni cilj ove studije jeste analiza mogućnosti primene informacionih tehnologija u sportu sa stanovišta neposrednih učesnika - sportista i trenera, sa jedne strane, ali i organizacionih struktura i gledalaca sa druge strane.

\section{METODE}

Za potrebe ove studije korišćen je bibliografsko-deskriptivni metod. Pretraga literature sprovedena uz pomoć sledećih servisa: PubMed, Google, Google Schoolar i Kobson. Ključne reči za traženje odgovarajuće literature bile su: sport, technology, IT, performance, training, competition, analysis.

\section{REZULTATI I DISKUSIJA}

Tehnologija se koristi za poboljšanje nastupa sportista u svim fazama - pre, za vreme i nakon događaja. Tehnologija se koristi u oblastima fizičke pripreme, zdravlja, opreme, odeće, obuće, objekata i površina za igru. Nosivi uređaji prate kardiovaskularne parametre sportiste, hiperbarična terapija kiseonikom pomaže oporavku nakon povrede, manji turbo motori u sportskim automobilima su ekonomičniji, kacige za biciliste su lakše i bolje su ozračene, patike sa kramponima su lakše i bolje prijanjaju pri kretanju, četvrta generacija (4G) terena se može koristiti bez obzira na vreme, tokom cele godine, veštački sneg omogućava da se zimski sportovi održavaju bilo gde u svetu.

IT koriste timovi za podršku sportista, kao što su treneri, medicinski radnici, skauti, kao i sami sportisti. IT ima važnu ulogu u praćenju i analizi učinka sportista, identifikujući kvalitete kao i područja za poboljšanje. IT se koristi i za prikupljanje i analizu podataka, što može pomoći u poboljšanju kondicije, poboljšanju veština, prevenciji povreda te pomoći u dobijanju utakmica učenjem različitih taktičkih rešenja.

Kreiranje informacionih sistema u sportskim organizacijama, podrazumeva kvalitetno sređene informatičke aktivnosti, kao i raspolaganje informatičkom tehnologijom, adekvatnim programima i kvalifikovanim kadrovima. Ovo pretpostavlja kvalitetno selektovanje, obradu, predstavljanje i plasiranje podataka u cilju napretka sporta [1].
IT u sportu pokriva tri segmenta učesnika, a to su:

1. sportisti i treneri,

2. zvaničnici, sudije i menadžeri i

3. publika.

Možda najvažniji uticaj IT u sportu jeste uticaj koji IT ima na direktne učesnike u sportu, odnosno na same sportiste i ljude koji upravljaju njihovom pripremom, trenere. IT obezbeđuje različite tipove podrške kojom se utiče na povećanje sportskog postignuća. Iako je danas trening i takmičenje teško odvojiti, načelno uticaj IT na ovu grupaciju može se podeliti na uticaj na treningu i uticaj na takmičenju. Kada se priča o treningu IT je napravio proboj u planiranju, kontroli i analizi primenjenog opterećenja, dijagnostici i analizi trenažne aktivnosti, dok se na takmičenju ogleda u tehnologiji kojom se prati (video) i kontrolišu odluke na takmičenje (fotofiniš, Hawk-eye, VAR).

IT pomaže trenerima da podrže svoje zahteve igračima kroz analize za vreme i nakon igre, te da sportisti preispitaju svoju taktiku i svoje protivnike kako bi utvrdili šta trebaju učiniti kako bi poboljšali i formulisali strategiju ili taktiku. IT pomaže sportistima da obaraju rekorde u različitim sportskim disciplinama. Ovi rezultati su direktan produkt naprednih tehnologija. Tehnologija omogućava mnoge benefite koji utiču na poboljšanje performansi, a samim tim i sportski rezultat. Pozitivni efekti se obezbeđuju kroz optimizaciju treninga i maksimizaciju koristi od treninga [2].

Nosivi uređaji (Wearable computers) predstavljaju poseban napredak u prostoru kontrole koji omogućavaju praćenje karakteristika sportista (frekvencija srca, krvni pritisak, metabolizam) u realnom vremenu. Od njihovog stvaranja, slučajevi dehidracije, srčanog udara ili smrtnog ishoda, dramatično su se smanjili. Kada je Kori Stringer preminuo od toplotnog udara tokom trening kampa svog NFL tima 2001. godine, kompanije su počele da istražuju načine praćenja vitalnih funkcija u realnom vremenu i izbegavaju ovakve tragedije. Tehnika koja se može nositi napravila je razliku u životima mnogih sportista, nadgledanjem frekvencije srca, hidratacije i temperature kroz svoj bežični i mikroskopski sistem praćenja zdravlja.

U vrhunskom sportu, gde se dostižu granične mogućnosti ljudskog organizma, veoma je važno nadzirati unutrašnje organe, temperaturu, varijabilnost otkucaja srca. Međutim, često ne postoji mogućnost da se ovi parametri provere. $U$ tu svrhu koriste se nesvarljive tablete, koje iz gastrointestinalnog trakta šalju vitalne informacije o telu. Dakle, ako postoji bilo kakav problem 
u organizmu, može se rešiti pre bilo kakve nesreće. To će pomoći da se smanji broj smrtnih ishoda od iscrpljivanja, što je drugi najčešći razlog kod smrtnih slučajeva sportista.

Mnogi računarski programi se više ne koriste samo za osnovne informacije o imenima igrača ili o kretanju rezultata. Sada sistemi kao što je „Moj trener“ (miCoach Elite System) daju podatke trenerima o stanju sportiste u svim fazama igre. Bežičnom tehnologijom trener na računaru prati vitalne funkcije, fizički i psihički status, uz pomoć senzora koji se nalaze na sportistima. Samim tim trener ima jasnu sliku i može pravovremeno doneti adekvatne odluke u korist sportiste [3].
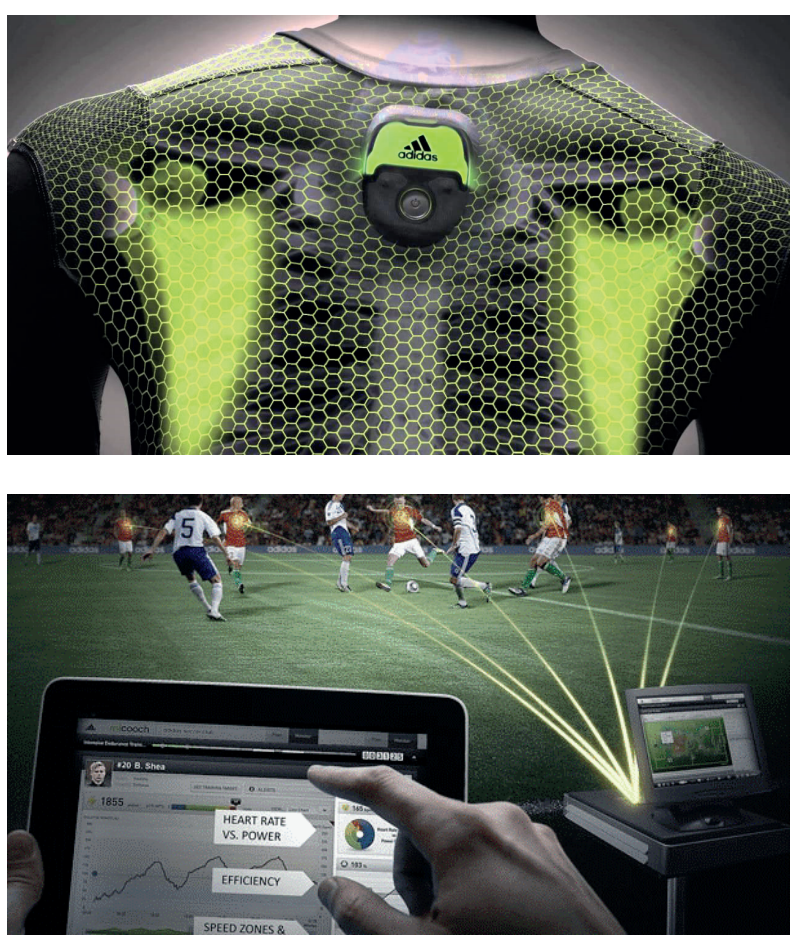

Slika 1. MiCoach elite system

Protetski uređaji za sportiste sa invaliditetom, su ono što je nekada bilo potpuno imaginarno, a danas predstavlja novi početak. Ljudi sa invaliditetom nekada nisu imali priliku da se takmiče, ali sa napredovanjem protetske tehnologije sve više i više fizički hendikepirani se takmiče, kao i osobe bez invaliditeta. Dr. Rori A. Cooper je lider u razvoju vrhunske protetike. Kao direktor laboratorija za ljudske inženjerske resurse na Univerzitetu u Pitsburgu, Dr. Cooper oblači sportiste u odela sa ugrađenim senzorima pokreta. Sportisti zatim prolaze kroz niz vežbi baziranih na sportskim pokretima, a kamerama i nosivom tehnologijom dobijaju izveštaje o svojim kretanjima. Procesni dizajn počinje nakon ove dijagnostike kretanja, koji na kraju stvara prilagođeno protetsko pomagalo koje se kreće zajedno sa telom sportiste [4].

$\mathrm{Na}$ samom takmičenju osim direktne koristi koje ima sam sportista, IT pomaže i sudijama u donošenju odluka, a samim tim utiče na regularnost takmičenja. Problem nastaje još u 19. veku jer je postalo preteško odrediti pobednika na konjičkim trkama. Nastaje nova tehnologija foto-finiš (eng. photo-finish) koja je prvi put postavljena na Olimpijskim igrama u Stokholmu, 1912. godine. Automatski fotografski uređaj zajedno sa preciznim elektronskim časovnikom beleži sliku i vreme svakog od takmičara koji je prešao ciljnu ravninu. Foto-finiš funkcioniše tako što se kroz usku vertikalnu pukotinu pomoću kamere snima cilj pomerajući film u smeru kretanja takmičara. Na ovaj način dobija se precizna slika i vreme svakog takmičara i postiže se visok nivo regularnosti takmičenja.

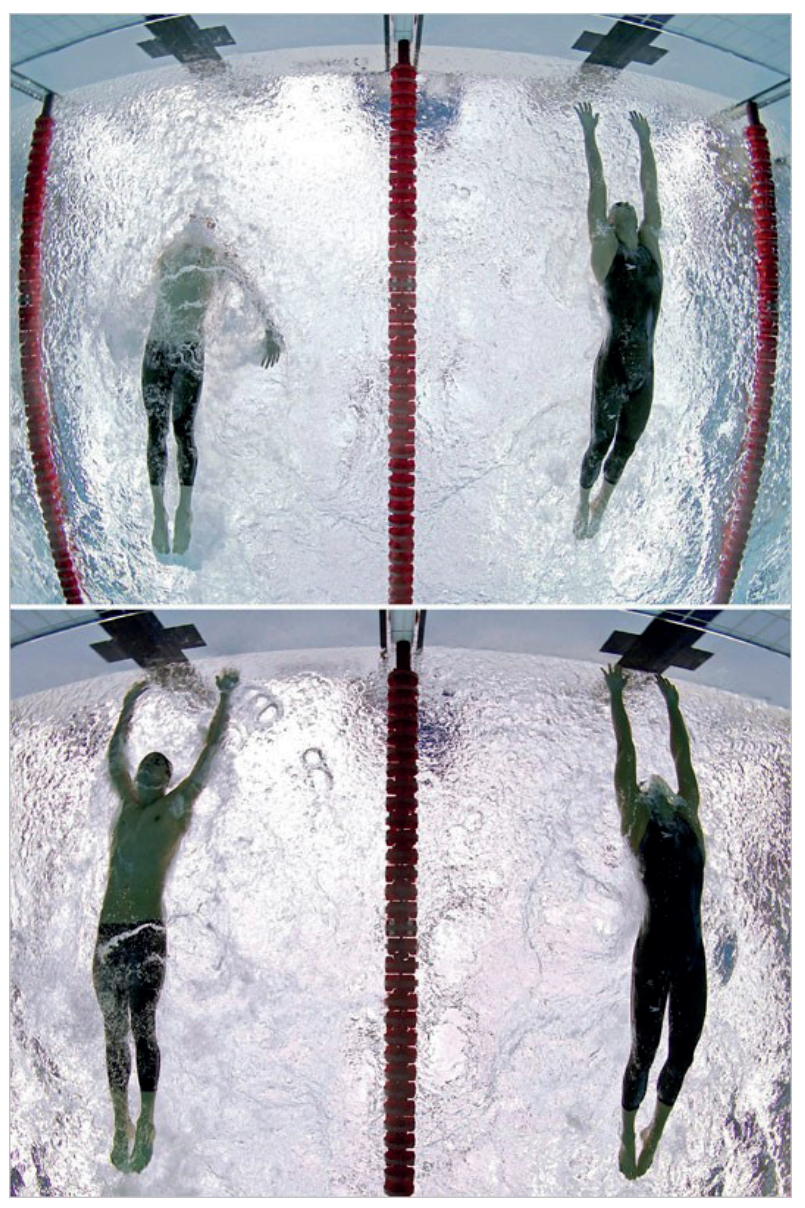

Slika 2. Foto-finiš analiza finala u disciplini $100 \mathrm{~m}$ delfin stilom na OI u Pekingu 2008. godine 
Hawk-eye („Oko sokolovo“) predstavlja jedan od najpoznatijih video sistema koji je razvijen krajem prošlog i početkom ovog milenijuma. Dr Pol Hokins je stručnjak koji je 2001. godine i zvanično završio i predstavio ovaj sistem. Hawk-eye uz pomoć super brzih kamera prati putanju lopte. Kamere su postavljene iznad terena i istovremenim snimanjem i proračunavanjem određuje najverovatniju putanju lopte. Nakon analize dobija se 3D slika kretanja lopte. Moguća greška je u proseku 3,6 mm. Ovom 3D slikom svi akteri meča, igrači, sudije i gledaoci mogu razjasniti dileme da li je lopta u terenu ili van njega, da li je lopta prešla gol liniju i sl. U tenisu sistem beleži i statistiku gde su padale loptice na terenu tokom različitih segmenata igre, tako da igrači i treneri mogu analizirati i svoju i igru protivnika te na osnovu toga graditi svoju taktiku. Na teniskim ili odbojkaškim mečevima, a u poslednje vreme i fudbalskim mečevima (VAR tehnologija) gde se ovaj sistem najviše koristi publika aktivno učestvuje. $U$ analizi preko velikih ekrana i kroz neizvesnost iščekivanja uživaju u sportskoj predstavi. Sudije su na ovaj način pošteđene teških odluka i negodovanja igrača i publike. Sve ovo omogućava veću regularnost takmičenja [5].
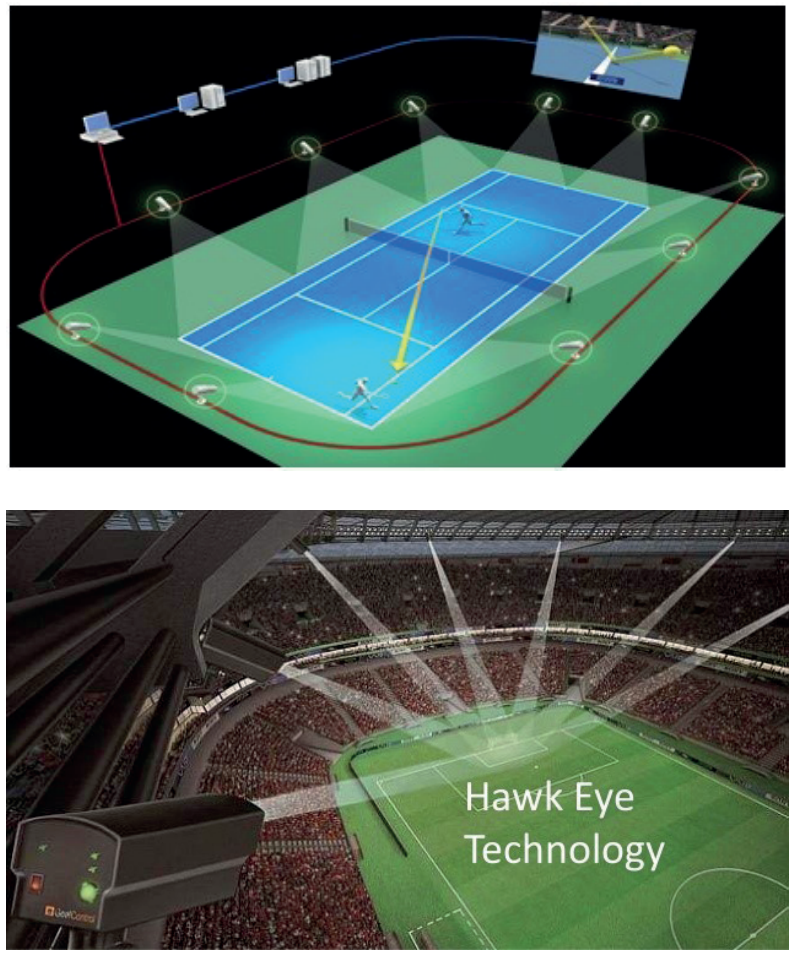

Slika 3. Hawk-eye sistem u tenisu i fudbalu

Gol-line (gol tehnologija) omogućava precizan odgovor da li je lopta prešla gol liniju i da li je regularan gol. Potreba za ovom tehnologijom se javila zbog odlučujućih golova koji nisu priznati na fudbalskim utakmicama koje su se igrale na Svetskim prvenstvima, klupskim utakmicama visokog uloga, iako je lopta celim svojim obimom bila unutar gola. Ovo je dovelo do toga da se stvori ovakva tehnologija i prvi put isproba 2012. godine na svetskom klupskom prvenstvu u Japanu. Tehnologija se pokazala kao $100 \%$ precizna, što dovodi od strane FIFA do priznavanja ovog sistema i uvođenja na Svetskom prvenstvu u Brazilu, 2014. godine. Takođe, engleska fudbalska liga je prva liga koja je uvela da se na svim stadionima postavi ova tehnologija od sezone 2013-14. Korišćenjem brzih kamera ili niskofrekvetnog magnetnog polja oko gola i elektronskog polja u samoj lopti, dobija se brz odgovor da li je gol postignut i to se očitava na ručnom satu glavnog sudije. Gol-line tehnologija je omogućila da više neće biti dilema da li je gol postignut ili ne. Par godina kasnije tehnologija je unapređena u VAR tehnologiju kako bi se pokrilo više segmenata igre [6].

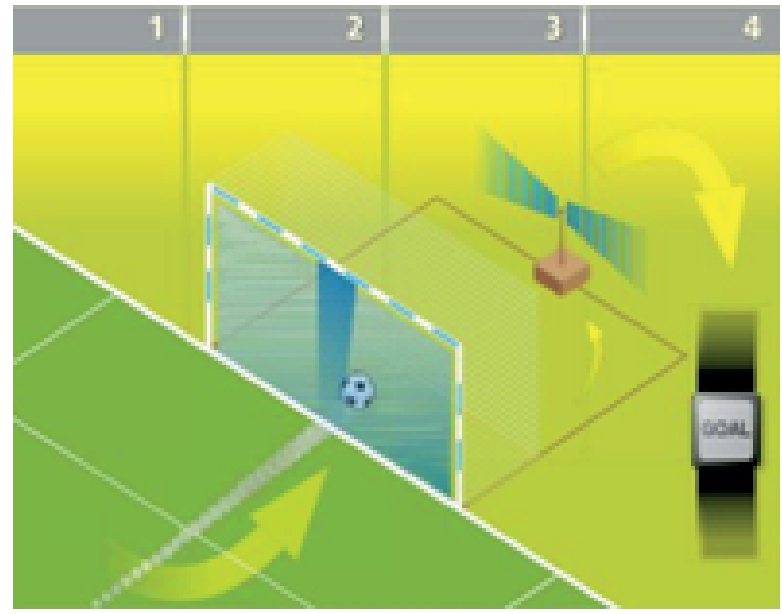

Slika 4. Gol tehnologija u fudbalu

Video tehnologija pre 1980. godine je najbolje opisati sa presedanom „Čudo na ledu“ koje nije emitovano uživo. Epska olimpijska hokejaška bitka između SAD-a i SSSR-a, koju su SAD osvojile, bila je na kašnjenju na kaseti, završivši se više od sat vremena pre početka TVemitovanja. Danas je sve uživo, i to ne samo na kućnom televizoru, već na vašem pametnom telefonu, tabletu i računaru. $U$ današnjem sportskom svetu nikada niste daleko od pristupa uživo te se iskustvo gledanja sporta dramatično promenilo na bolje. 3D tehnologija za prenos utakmica je tehnologija koja je stvorena za gledaoce koji iz svoje fotelje gledaju prenos utakmice i uz pomoć 
3D naočara kao da su na samom terenu pored igrača. 26. Januara 2010. godine odigrana je prva utakmica koja je odigrana između Arsenala i Mančester Junajteda i prenošena u 3D tehnologiji. Ovaj sistem je televizija SKY razvijala dve godine [7].

Kako bi bolje razumeli sastavne delove koji promovišu sportski uspeh, video i statistička analiza preuzele su važno mesto u pripremi sportista za takmičenja. U sportskim igrama, uspešnost na takmičenju predstavlja interakciju različitih tehničkih, taktičkih, fizičkih i psiholoških faktora. Savremene analize, na osnovu video snimka utakmice, obezbeđuju tehničko-taktičke obrasce kretanja pojedinca i ekipe (precizna/neprecizna dodavanja, dobijeni/izgubljeni dueli, udarci glavom, pasovi na različitim distancama, ofanzivne/defanzivne obrasce kretanja, interakcije između igrača u pojedinim zonama...) i fizičke parametre pojedinca i grupe (pretrčana distanca, pretrčane distance u pojedinim zonama opterećenja, parametri u pojedinim delovima utakmice...) $[8,9]$.

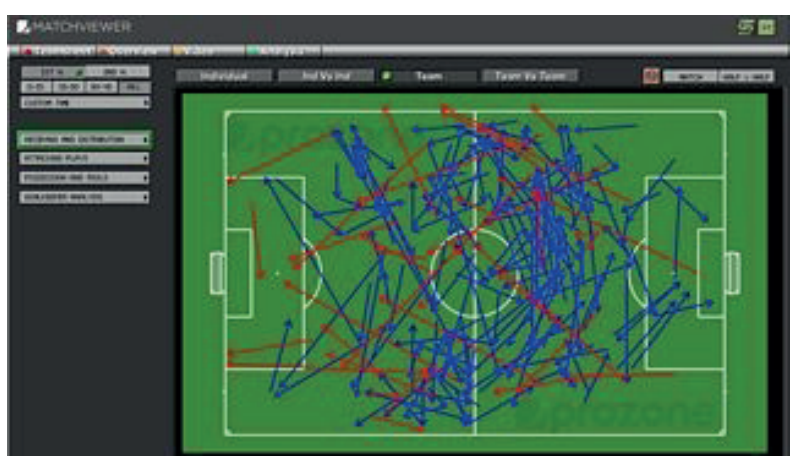

Slika 5. Prikaz analize kretanja igrača tokom utakmice

Informaciona tehnologija igra ključnu ulogu u tome kako se sport igra i gleda. To znači da su zvaničnici, gledaoci i mediji povezani tokom nastupa [10].

Tehnologija oblikuje kako zvaničnici upravljaju kvalitetom prvenstveno kroz:

- komuniciranje pomoću slušalice i mikrofona sa kojim se konsultuju sa drugim zvaničnicima na i izvan terena

- Kod donošenje odluka, omogućena je reprodukcija snimaka za gledanje događaja iz različitih uglova kako bi se donela ispravna odluka.

- Praćenje lopte kako bi se obezbedila tačnost odluka u tenisu, fudbalu ili odbojci.

- Preciznije merenje dužine skokova i daljina izbačaja različitih rekvizita uz pomoć laserske tehnologije
- Praćenje vremena, merenjem vremena u napadu u košarci ubrzava se igra i održava se uzbuđenje

- Vođenje evidencije računarima za praćenje dobrih poteza i grešaka za više sportista odjednom.

Na kraju, gledaoci sportskog događaja nisu više pasivni posmatrači kod kuće ili na stadionu. Tehnologija je omogućila gledaocima da imaju aktivniju ulogu u događajima na različite načine:

- Kroz pokrivenost događaja fotoaparatima na daljinsko upravljanje i mikro-kamerama pružaju više uglova gledanja, prate pojedinačne sportiste ili sve izvođače.

- Kroz statističke informacije - o pojedincima, utakmici i prethodnim nastupima koje su dostupne na ekranu ili klikom na dugme tokom igre.

- Interaktivne aplikacije nude pristup robama, informacijama, takmičenjima, igrama i glasanju preko veza na ulaznicama i programima ili preko preuzimanja.

- Digitalni mediji omogućuju da ljubitelji sporta mogu pratiti širok spektar amaterskih i profesionalnih sportova na mnogo različitih načina, na telefonu, tabletu, laptopu, računaru.

- Društveni mediji dozvoljavaju fanovima da imaju ličnu vezu sa svojim sportskim herojima i klubovima.

\section{ZAKLJUČAK}

Informacione tehnologije igraju vitalnu ulogu u životu ljudi, posebno u polju sporta i igara. One pomažu da se izbegnu greške $u$ organizaciji i administraciji $u$ sportu na različitim nivoima, posebno na onom vrhunskom. Informacione tehnologije u sportu prerastaju u posebnu naučnu disciplinu. Istraživačke aktivnosti, unapređeno učenje i vođenje treninga, biomehaničke analize i terenska istraživanja i dalje evoluiraju. Unapređenje zdravlja, priprema treninga, video analize, procena fizičkih sposobnosti, čuvanje rezultata, analiza učinka tima u toku utakmice, predstavljaju samo neka od polja u kojima informacione tehnologije nalaze svoju primenu u modernom sportu. Kao takve mogu se iskoristiti za ostvarivanje zadatih ciljeva u svim oblastima koje pokrivaju sport. 


\section{LITERATURA}

[1] J. Malacko. Modelovanje strategijskog menadžmenta u sportu. Sport Science, Vol 1, No 1, pp. 12-17, 2008

[2] K.A. Ramesh. Role of information technology in enhancing sports performance. International Journal of Physical Education, Sports and Health. Vol. 3, No. 5, pp. 277-279, 2016

[3] S. Vasquez. Adidas miCoach Elite System Provides Trainers and Players with Real-Time Performance Metrics. https://www.sporttechie.com/adidas-micoach-elite-system-provides-trainers-and-playerswith-real-time-performance-metrics/, 2013

[4] R.A. Cooper et al. Engineering and Technology in Wheelchair Sport. Physical Medicine and Rehabilitation Clinics of North America, Vol. 29, No. 2, pp.347-369, 2018

[5] B. Bal and G. Dureja, Hawk Eye: A Logical Innovative Technology Use in Sports for Effective Decision Making. Sport Science Review, Vol. 21, No. 1-2, pp. 107-119, 2012
[6] P. Spagnolo, P.L. Mazzeo, M. Leo, E. Stella \& A. Distante, Non-Invasive Soccer Goal Line Technology: A Real Case Study. IEEE Conference on Computer Vision and Pattern Recognition Workshops, 2013

[7] B. Clapp. Six Technological Advancements That Have Changed Sports. https://www.workinsports. $\mathrm{com} / \mathrm{blog} /$ six-technological-advancements-thathave-changed-sports/, 2016

[8] H. Sarmento, R. Marcelino, M.T. Anguera, J. Campanico, N. Matos \& J. Leitäo, Match analysis in football: a systematic review. Journal of Sports Sceinces, Vol. 32, No. 20, pp. 1831-1843, 2014

[9] M. Silva, R. Marcelino, D. Lacerda and P.V. João, Match Analysis in Volleyball: a systematic review. Montenegrin Journal of Sports Science and Medicine, Vol. 5, No. 1, pp. 35-46, 2016

[10] Technology in sport. https://www.bbc.com/bitesize/ guides/zw4gk7h/revision/1 